\title{
Unusual supramolecular assembly and nonlinear optical properties of L-histidinium hydrogen malate
}

\author{
E. de Matos Gomes ${ }^{\mathrm{a}, *}$, V.H. Rodrigues ${ }^{\mathrm{b}}$, M.M.R. Costa ${ }^{\mathrm{b}}$, M.S. Belsley ${ }^{\mathrm{a}}$, P.J.M. Cardoso ${ }^{\mathrm{a}}$, \\ C.F. Gonçalves ${ }^{\mathrm{a}}$, F. Proença ${ }^{\mathrm{c}}$ \\ ${ }^{a}$ Departamento de Física, Universidade do Minho, Campus de Gualtar 4710-057, Braga, Portugal \\ ${ }^{\mathrm{b}}$ Departamento de Física, Faculdade de Ciências e Tecnologia, Universidade de Coimbra, 3004-516 Coimbra, Portugal \\ ${ }^{\mathrm{c}}$ Departamento de Química, Universidade do Minho, Campus de Gualtar 4710-057, Braga, Portugal
}

Received 16 February 2006; received in revised form 18 April 2006; accepted 1 May 2006

Available online 13 May 2006

\begin{abstract}
A new nonlinear optical material, L-histidinium hydrogen malate, has been synthesized. The crystal structure was determined at $90 \mathrm{~K}$ by single-crystal X-ray diffraction in order to analyze its supramolecular structure. A new building block type has been found. The malate anions form head-to-side infinite chains parallel to [100], via $\mathrm{O}-\mathrm{H} \cdots \mathrm{O}$ interactions, instead of the usual head-to-tail infinite chains found in other hydrogen malate salts. The L-histidine cations form chains parallel to [100] via $\mathrm{N}-\mathrm{H} \cdots \mathrm{O}$ hydrogen bonds, with cations of adjacent chains in anti-parallel way. The compound shows a good optical second-harmonic generation capability with an effective second-order susceptibility estimated to be 0.70 of that for potassium dihydrogen phosphate.
\end{abstract}

(C) 2006 Elsevier Inc. All rights reserved.

Keywords: Dicarboxylates; Hydrogen bonds; Molecular crystals; Supramolecular assemblies; Second-harmonic generation; Nonlinear optical materials

\section{Introduction}

One of the most successful strategies for engineering crystal structures takes advantage of the strong directional orientation capability of hydrogen bond interactions between molecules to control molecular self-assembly during crystallization. The individual molecules organize themselves into supramolecular aggregates that have welldefined structures often resulting in unique chemical and physical properties [1-5]. For the past two decades, extensive efforts have been directed toward the design and synthesis of efficient chromophores, which can be incorporated into macroscopic assemblies such as polymers, to form materials exhibiting large nonlinear optical and electro-optic responses [6-11]. A successful example is the case of octupolar nonlinear materials pioneered by the group of Zyss et al. [12] and Feuvrie et al. [13] that have been successfully tailored and attempts for supramolecular

\footnotetext{
*Corresponding author. Fax: + 351253678981.

E-mail address: emg@fisica.uminho.pt (E. de Matos Gomes).
}

associations between cationic and anionic octupolar derivatives have been made very recently. In the design of new materials for nonlinear optical applications, hydrogen bonding often takes on an especially important role. Hydrogen bonds have been used to construct molecular building blocks with structures that can be controlled in both one and two dimensions and very large nonlinear optical and electro-optic responses have been obtained in hydrogen-bonded organic crystals and thin films [5,14-16]. Phenomenological rules describing the general tendencies of hydrogen-bonded building blocks or supramolecular synthons, as they are sometimes called in the literature, are now well established in crystal engineering where the groups led by Desiraju $[1,17,24]$ and Aakeroy and Hitchcock[18], Aakeroy and Seddon [20], Aakeroy et al. [22] have made decisive contributions. Recently, the concept has been extended to the particular case of co-crystals and salts between organic molecules and dicarboxylic acids [17-27]. Generally the mono-anions of dicarboxylic acids form hydrogen-bonded chains. The anions in these chains align head-to-tail with a carboxylic group (head) linked to 
the carboxylate moiety (tail) of another anion by strong $\mathrm{O}-\mathrm{H} \cdots \mathrm{O}$ hydrogen bonds [28-33]. We discuss in this contribution a striking exception to this general tendency, L-histidinium hydrogen malate.

The formation of supramolecular arquitectures in salts of dicarboxylic acids has been discussed for a large number of compounds. In particular, imidazole and the dicarboxylic L-tartaric and L-malic acids have been investigated as molecular building blocks. Previous studies have shown that the mono-anions of dicarboxylic acids form hydrogenbonded chains. Although the oxygen atom on the hydroxyl group can also accept hydrogen bonds, the negatively charged carboxylate group is the stronger acceptor [34], the anions in those chains align head-to-tail with a carboxylic group by strong $\mathrm{O}-\mathrm{H} \cdots \mathrm{O}$ hydrogen bonds.

L-histididine is an extremely interesting molecule; in addition to its important biological properties [35-38], it has been used in supramolecular assemblies and crystal engineering of nonlinear optical crystalline materials [39-40]. In the crystalline compound L-histidinium tartrate hemihydrate [41], the tartrate anions form $\mathrm{COOH}-\mathrm{COO}^{-}$ head-to-tail chains similar to the structures observed in all previously studied dicarboxylate mono-anions. The selfassembling building block formed by the L-tartrate anion and the L-histidine cation originates an overall threedimensional (3D) supramolecular network.

However, in L-histidinium hydrogen malate, the malate anions do not follow any of these patterns. The supramolecular assembling in this material highlights the difficulties still encountered in crystal engineering, as the building of solid-state materials does not always happen in a predictable way. In fact, the L-histidinium hydrogen malate salt is an excellent example of the difficulty expressed by Maddox [42]: "One of the continuing scandals in the physical sciences is that it remains, in general, impossible to predict the structure of even the simplest crystalline solids from knowledge of their chemical composition."

\section{Experimental section}

\subsection{Synthesis and infrared spectroscopy}

A water solution $(60 \mathrm{~mL})$ of equimolar $(0.01 \mathrm{~mole})$ analytical grade reagents L-histidine $(99.5 \%)$ and L-malic acid $(99,5 \%)$, purchased from Aldrich, was stirred at $50{ }^{\circ} \mathrm{C}$ for $3 \mathrm{~h}$ and allowed to cool down to room temperature inside a glass beaker. Colorless prismatic crystals were obtained after 5 days of evaporation at ambient temperature. Crystals were further recrystalised from a water solution $1.5 \times 10^{-3}$ molar at room temperature, during 10 days, and used for structural and optical studies.

Polycrystalline powders were obtained by grinding the obtained crystals in an agate mortar with a pestle. The infrared vibrational measurements were carried out at room temperature. The infrared spectrum was obtained by suspending the polycrystalline powder in oil (nujol), kept between $\mathrm{NaCl}$ wafers, and was recorded on a Bomem
Michelson MB-Series FT-IR spectrometer, in the region $4000-500 \mathrm{~cm}^{-1}$. The resolution was set at $4 \mathrm{~cm}^{-1}$ and the spectrum was averaged over 10 separate scans. The melting point, measured using a Stuart SMP3 apparatus, is between 171 and $174^{\circ} \mathrm{C}$, followed by decomposition.

\subsection{Crystal structure determination}

Single crystal X-ray data were collected on an EnrafNonius CAD4 diffractometer with graphite-monochromated $\operatorname{MoK} \alpha$ radiation $(\lambda=0.71073 \AA)$ and $\omega-2 \theta$ scans at $90 \mathrm{~K}$. Table 1 lists the experimental and crystal data. The structure was solved by direct methods using SHELXS-97 [43]. All $\mathrm{H}$ atom positions were geometrically generated and subsequently refined as riding with the distance atomhydrogen allowed to refine according to SHELXS-97 defaults. Examination of the crystal structure with PLATON [44] showed that there are no solvent-accessible voids in the crystal lattice. All nonhydrogen atoms were refined anisotropically.

\subsection{Linear and nonlinear optical studies}

The transmission curve of a 0.5 -mm-thick plate was measured between 200 and $1500 \mathrm{~nm}$ using a Shimadzu spectrophotometer.

Optical second-harmonic generation was measured on polycrystalline samples using the standard Kurtz and Perry technique [45]. The fundamental beam of a Q-switched

Table 1

Crystal data and structure refinement for L-histidinium hydrogen malate

\begin{tabular}{ll}
\hline Empirical formula & $\mathrm{C}_{10} \mathrm{H}_{15} \mathrm{~N}_{3} \mathrm{O}_{7}$ \\
Formula weight & 289.25 \\
Temperature & $90(2) \mathrm{K}$ \\
Wavelength & $0.71073 \AA$ \\
Crystal system & Orthorhombic \\
Space group & $P 2_{1} 2_{1} 2_{1}$ \\
Unit cell dimensions & $a=5.2148(7) \AA, \alpha=90^{\circ}$ \\
& $b=13.5259(18) \AA, \beta=90^{\circ}$ \\
& $c=17.5369(19) \AA, \gamma=90^{\circ}$ \\
Volume & $1237.0(3) \AA^{3}$ \\
$Z$ & 4 \\
Density (calculated) & $1.553 \mathrm{mg} / \mathrm{m}^{3}$ \\
Absorption coefficient & $0.133 \mathrm{~mm}{ }^{-1}$ \\
$F(000)$ & 608 \\
Crystal size & $0.3 \times 0.2 \times 0.1 \mathrm{~mm}{ }^{3}$ \\
Theta range for data collection & $2.77-27.43^{\circ}$. \\
Index ranges & $-3 \leqslant h \leqslant 6,-5 \leqslant k \leqslant 17,-6 \leqslant l \leqslant 22$ \\
Reflections collected & 1808 \\
Independent reflections & $1666[R($ int $)=0.0328]$ \\
Completeness to theta $=27.43^{\circ}$ & $99.9 \%$ \\
Absorption correction & None \\
Refinement method & Full-matrix least-squares on $F^{2}$ \\
Data/restraints/parameters & $1666 / 0 / 184$ \\
Goodness-of-fit on $F^{2}$ & 1.100 \\
Final $R$ indices $[I>2$ sigma $(I)]$ & $R_{1}=0.0436, \mathrm{w} R_{2}=0.1112$ \\
$R$ indices (all data) & $R_{1}=0.0924, \mathrm{w} R_{2}=0.1279$ \\
Largest diff. peak and hole & 0.368 and $-0.403 \mathrm{e} \AA^{-3}$ \\
\hline
\end{tabular}


Nd:YAG laser with a $1064 \mathrm{~nm}$ wavelength, energy of approximately $20 \mathrm{~mJ}$, pulse duration of roughly $7 \mathrm{~ns}$ and a $10 \mathrm{~Hz}$-repetition rate was weakly focused to a spot size of approximately $1 \mathrm{~mm}$ diameter on the samples. The material was particle sized using a set of standard microsieves (Retsch) having mesh width between 50 and $160 \mu \mathrm{m}$. The sample cell consisted of a microscope slide with a depression of $3 \mathrm{~mm}$ diameter and $0.5 \mathrm{~mm}$ thickness covered with a flat microscope slide. The generated secondharmonic signal was compared with that generated by polycrystalline potassium dihydrogen phosphate (KDP) with the same grain size and similar sample preparation.

\section{Results and discussion}

\subsection{Crystal structure}

In the title compound, the asymmetric unit of which is shown in Fig. 1, the L-histidine cation is monopositively charged with a protonated and positively charged amino and imidazole groups and a negatively charged carboxylate group. The amino group takes part in five hydrogen bonds three of which have one carboxylate oxygen atom of another cation as acceptor. In the remaining two hydrogen bonds, the acceptors are the oxygen atoms of the L-malate anion carboxylate group. The L-histidine cations form chains along [100], as shown in Fig. 2. In these chains, the $\mathrm{COO}^{-}$group of one cation is hydrogen bonded to two $\mathrm{NH}_{3}$ groups of neighboring cations. These cations also form antiparallel pairs via two symmetry related $\mathrm{N}-\mathrm{H} \cdots \mathrm{O}$ hydrogen bonds; the latter are further connected by L-malate anions also through $\mathrm{N}-\mathrm{H} \cdots \mathrm{O}$ bonds (Table 2 and Fig. 3).

The L-malate anions form 1-D hydrogen-bonded chains along [100]. Rather than being aligned in the usual head-totail arrangement they assume a novel head-to-side config-

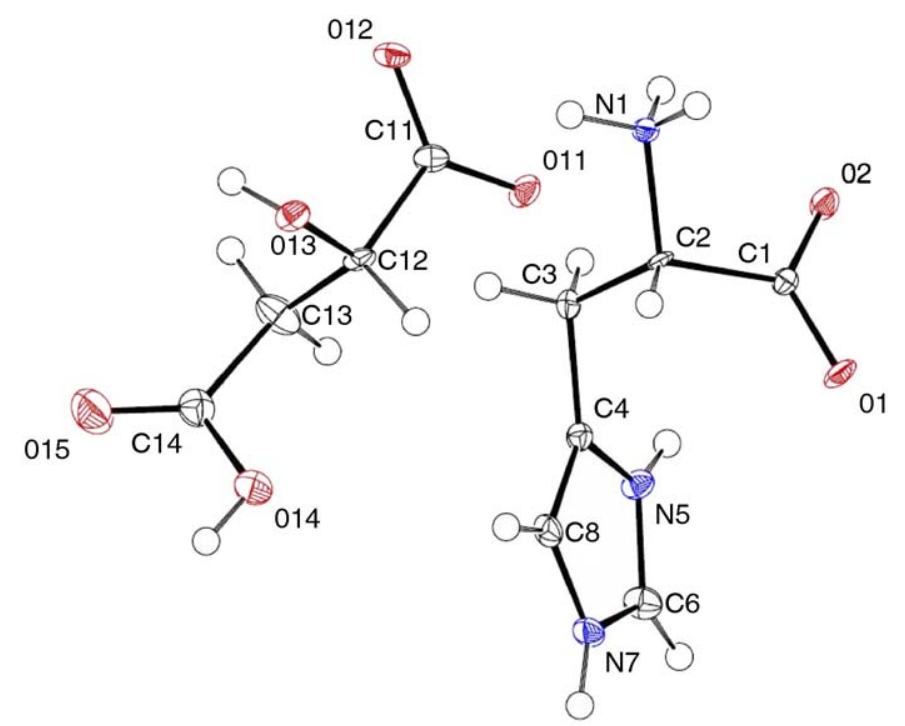

Fig. 1. Molecular structure (thermal ellipsoids at 50\% probability) and the atom numbering scheme for L-histidinium hydrogen malate (PLATON). uration. As has been well documented in the articles by Macdonald and Iversen [25], Trivedi et al. [26], Aakeroy and Hitchcock [30] and Aakeroy and Nieuwenhuyzen [31], the conventional head-to-tail arrangement has the donor $\mathrm{COOH}$ carboxylic group (tail) strongly hydrogen bonded to an acceptor carboxylate $\mathrm{COO}^{-}$group (head), creating infinite chains. In contrast, in the present material, the carboxylate $\mathrm{COO}^{-}$group of one anion is bonded to the side hydroxyl group $\mathrm{COH}$ of its neighbor. There are four chains per unit cell, two of them running up and the other two running down along $a$ axis, as shown in Fig. 4. This novel head-to-side configuration has, to our knowledge, not been observed before in any organic or semi-organic Lmalate salt.

Although in all L-malate salts, the carboxylate group has been found to be a stronger acceptor than the oxygen from the hydroxyl group, this is not observed in L-histidinium hydrogen malate. In fact, the strongest hydrogen bond in the structure occurs between the $\mathrm{O} 14$ atom of carboxylic group of the L-malate anion and the $\mathrm{O} 1$ atom belonging to the carboxylate group of the L-histidine cation. Consequently, the $\mathrm{COOH}$ carboxylic group from the anion is strongly hydrogen bonded to the cation $\mathrm{COO}^{-}$group and not to that of the anion. The two other strong hydrogen bonds binding the cations to the anions occur between the imidazole nitrogen atoms which act as donors and $\mathrm{O} 11$ and O13 acting as acceptors. The molecular building block (supramolecular synthon) is the pair formed by a $\mathrm{COO}^{-}$ group of L-malate anion bonded to one of the ring nitrogen atoms of the L-histidine cation. This synthon self-assembles forming 1-D chains along [100]. Each chain is interconnected with another chain, via $\mathrm{N}-\mathrm{H} \cdots \mathrm{O}$ hydrogen bond with a nitrogen atom of the cation ring, forming a 2-D subnetwork as can be seen in Fig. 5. The $\mathrm{COOH}$ group of the anion makes the bridge between adjacent 2-D networks to form an overall 3-D hydrogen-bonding network. In Fig. 6, a (001) projection shows the complex crystal structure forming open channels along [001]. There are four-member ring channels formed by two L-histidinium cations and two L-malate anions, and three-member ring channels formed by two L-histidinium cations and one L-malate anion with the $\mathrm{NH}_{3}$ group pointing toward the ring center.

\subsection{Assignment of IR bands}

The FT-IR spectrum is shown in Fig. 7. Most important for the above conclusions regarding the supramolecular assemblage is the presence of a very intense band at $1717 \mathrm{~cm}^{-1}$ that can be assigned to the $\mathrm{C}=\mathrm{O}$ stretching vibration of the carboxylic group. This observation supports the X-ray data which indicates that one of the carboxylic groups of the L-malate anion is not ionized. The two carboxylate ions lead to a broad and intense band at $1590 \mathrm{~cm}^{-1}$, that can be assigned to the anti-symmetric stretching vibration. The band at $1497 \mathrm{~cm}^{-1}$ is also intense and can be assigned to the symmetric stretching vibration. 


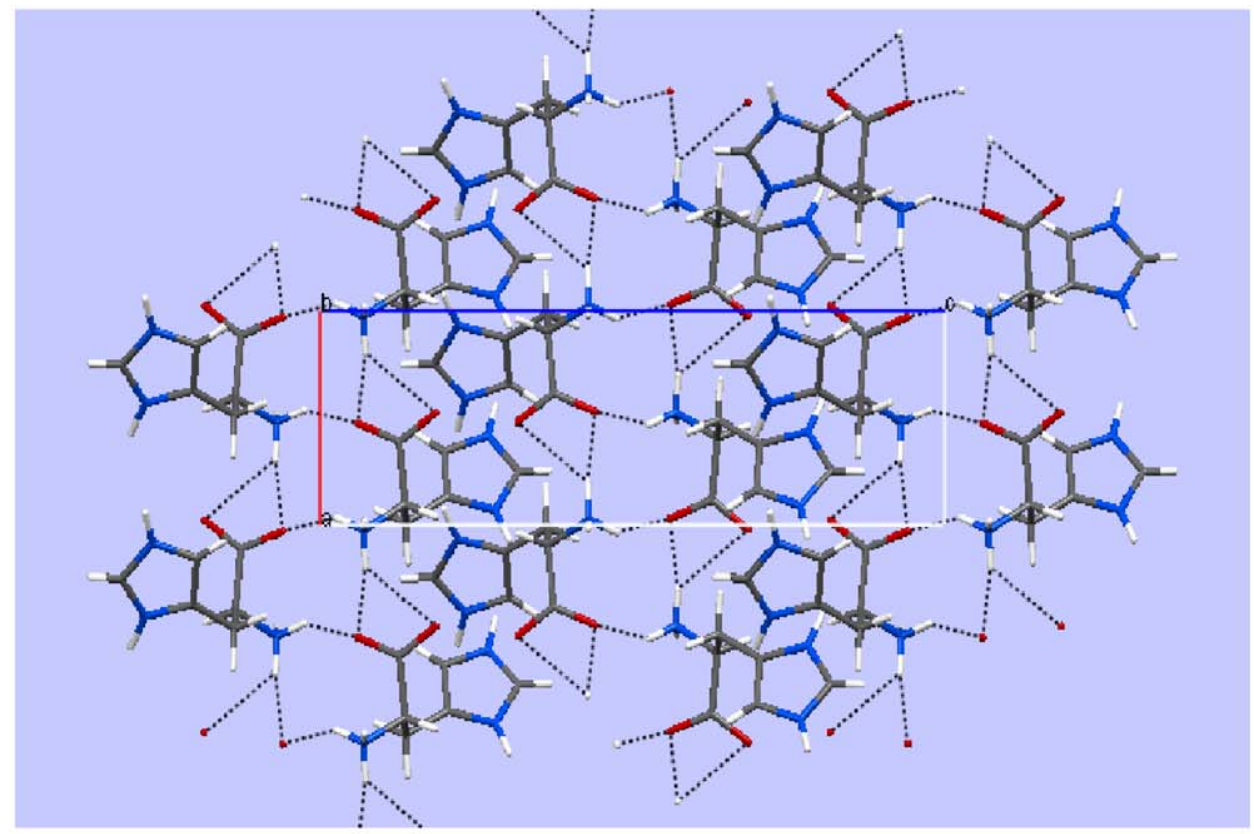

(a)

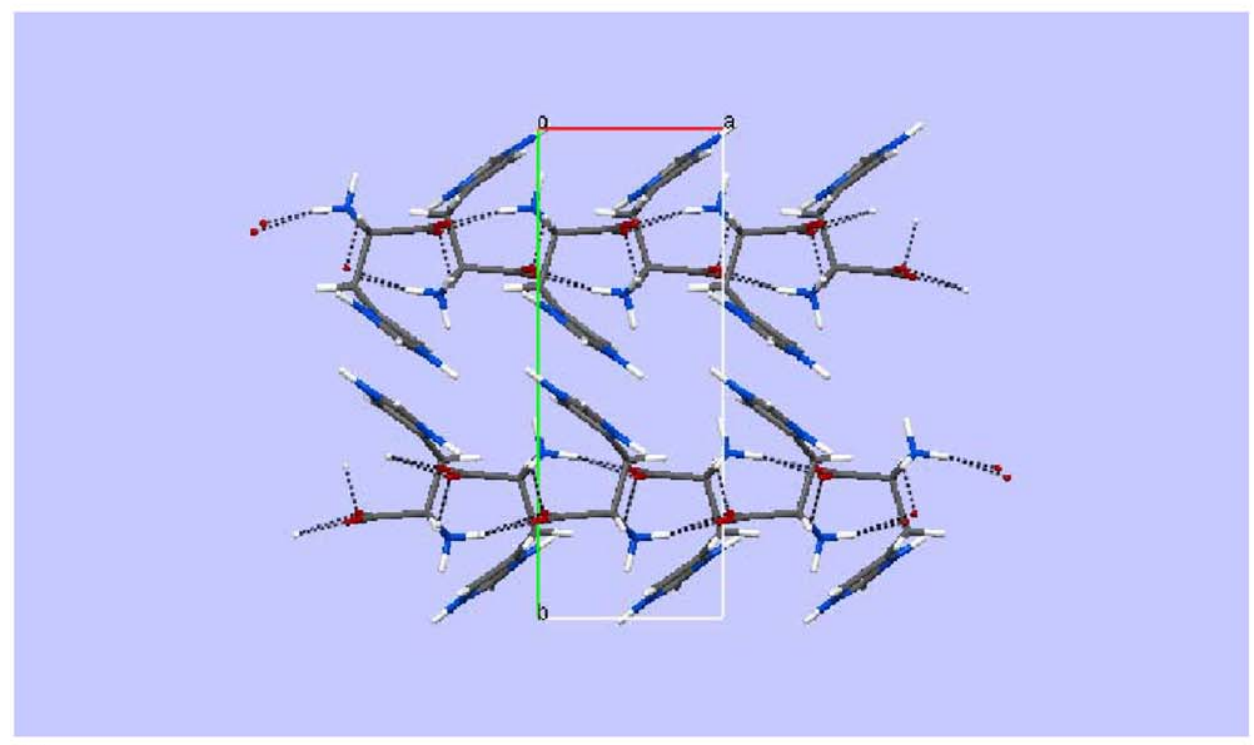

(b)

Fig. 2. A [010] (a) and [001] (b) view of L-histidine cation chains formed via $\mathrm{N}-\mathrm{H} \cdots \mathrm{O}$ interactions. The cations in adjacent chains are aligned in an antiparallel way.

Table 2

Hydrogen bonds [̊̊ and deg.] for L-histidinium hydrogen malate

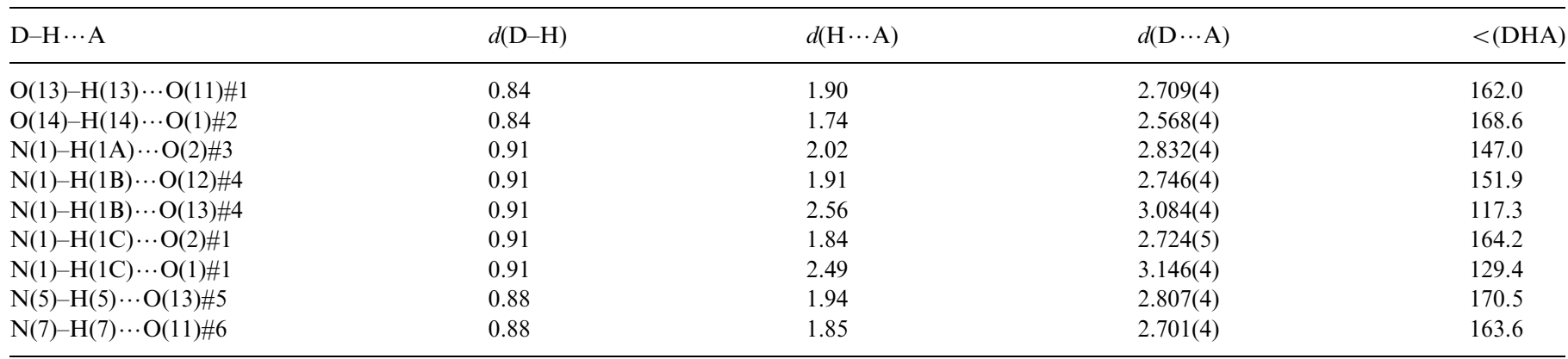

Symmetry transformations used to generate equivalent atoms: \#1 $x+1, y, z, \# 2-\mathrm{x}+1, y-1 / 2,-z+3 / 2, \# 3 x+1 / 2,-y+3 / 2,-z+2, \# 4 x-1 / 2,-y+3 / 2$, $-z+2, \# 5 x-1, y, z, \# 6-x+1 / 2,-y+1, z-1 / 2$. 


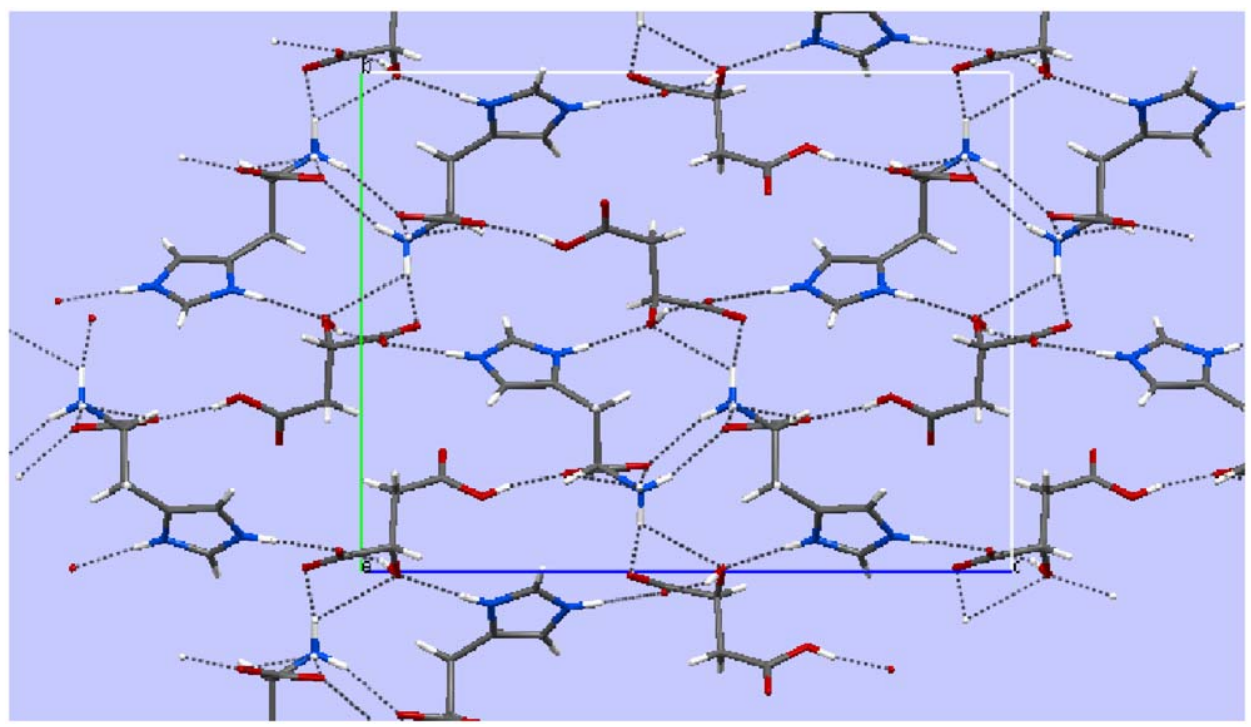

Fig. 3. An infinite anion-cation layer perpendicular to [100]. The L-histidinium molecules form anti-parallel pairs via $\mathrm{N}-\mathrm{H} \cdots \mathrm{O}$ hydrogen bonds, which are interconnected by malate anions also through $\mathrm{N}-\mathrm{H} \cdots \mathrm{O}$ hydrogen bonds.

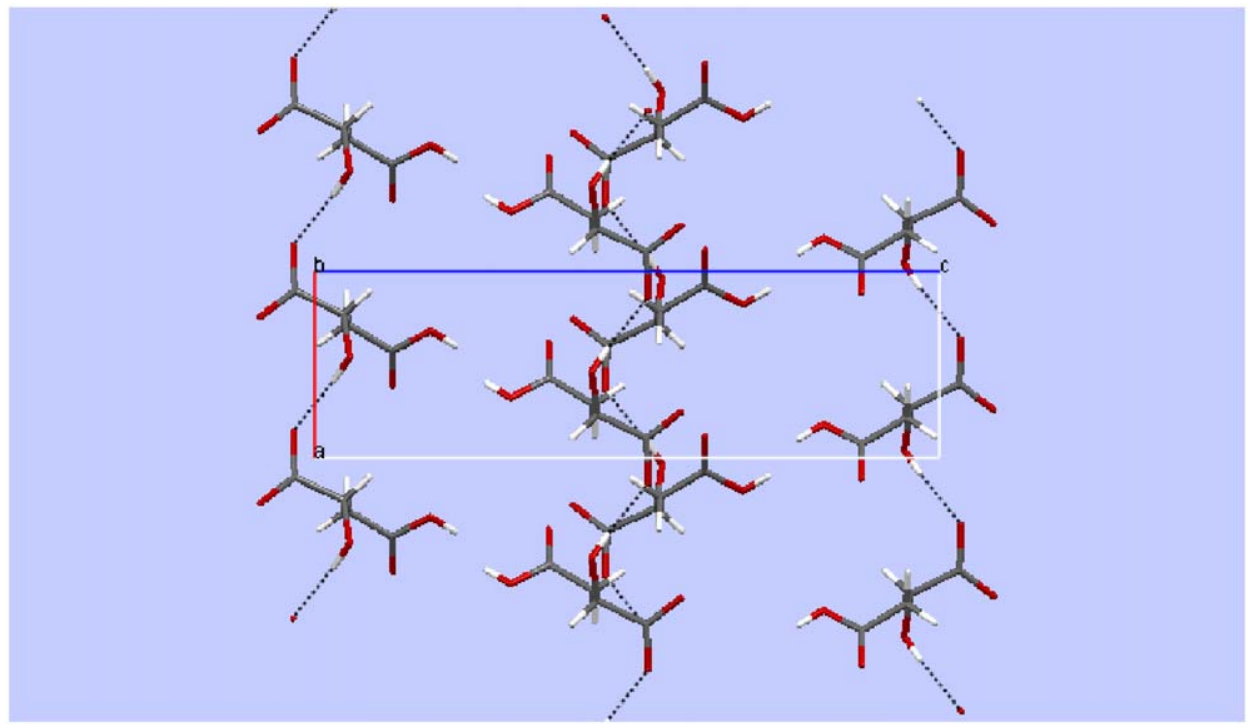

(a)

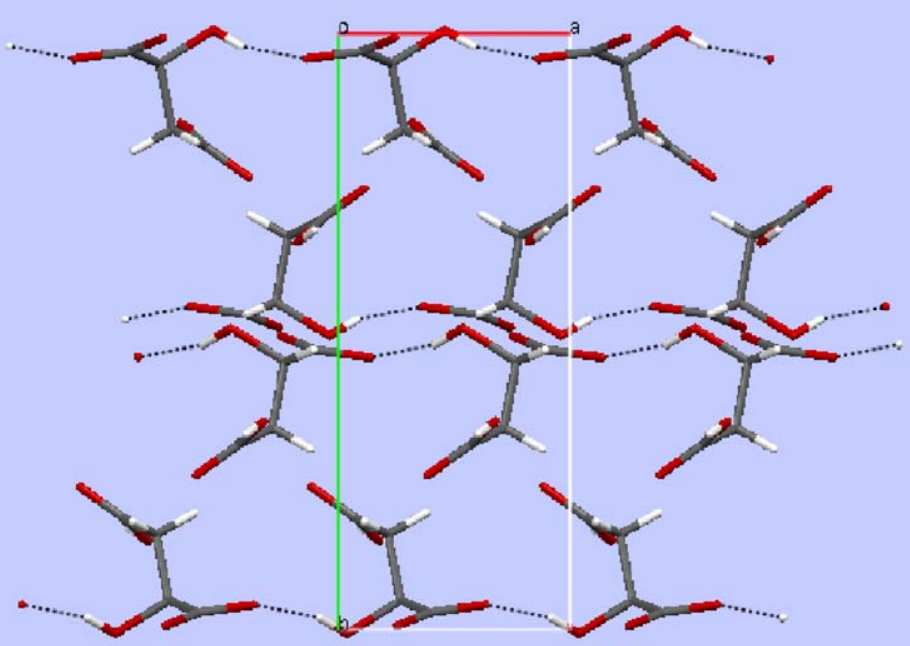

(b)

Fig. 4. One-dimensional malate chains running along [100]. The anions form head-to-side chains where the $\mathrm{COO}^{-}$group of one anion is hydrogen bonded to the $\mathrm{COH}$ side group of a neighbor one. View of the chains along [010] (a) and [001] b). 


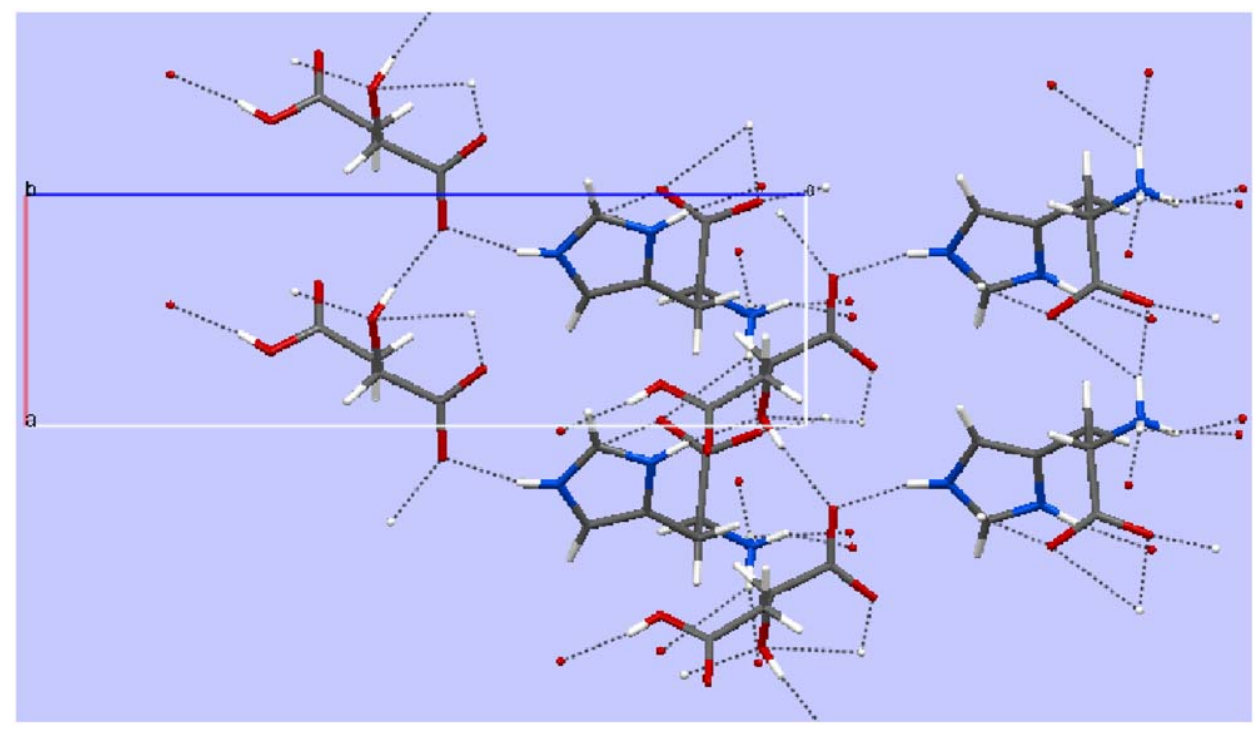

Fig. 5. Partial view of L-histidinium hydrogen malate down [010], showing the molecular building blocks formed by an L-malate anion and an L-histidine cation: the $\mathrm{COO}^{-}$anion group is hydrogen bonded to a cation $\mathrm{N}$ atom, forming a supramolecular synthon.

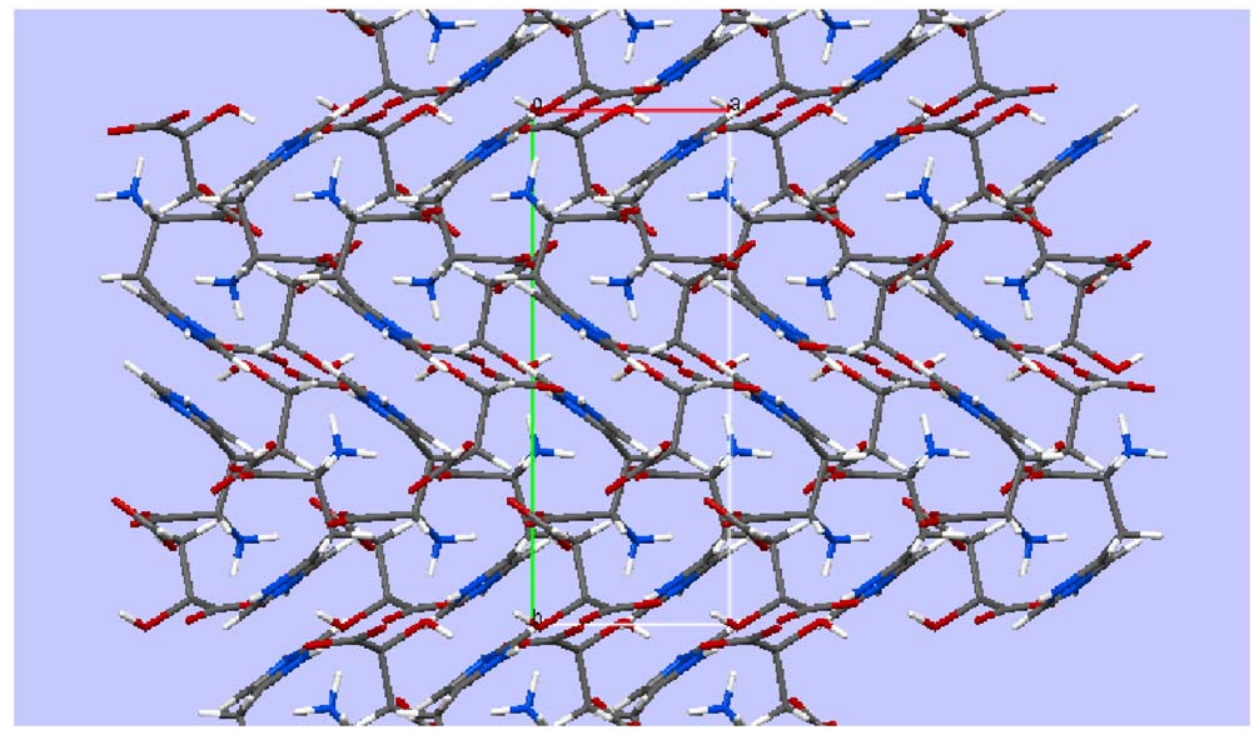

Fig. 6. A view of L-histidinium hydrogen malate structure showing the opened channels along [001]: a four-member ring formed by two L-histidinium cations and two L-malate anions and a three-member ring formed by two L-histidinium cations and one L-malate anion with the $\mathrm{NH}_{3}$ group pointing toward the ring center.

In addition, several intense bands are observed in the $1300-1050 \mathrm{~cm}^{-1}$ region, arising from the $\mathrm{C}-\mathrm{O}$ stretching vibrations, and the signals at $1295 \mathrm{~cm}^{-1}$ (vs), $1259 \mathrm{~cm}^{-1}$ (vs) and $1206 \mathrm{~cm}^{-1}$ (vs) can be assigned to this type of vibration. The band at $1032 \mathrm{~cm}^{-1}$ (s) can be attributed to ring anti-symmetric stretching vibrations of the fivemembered imidazole ring, while the band at $879 \mathrm{~cm}^{-1}$ (s) is assigned to the symmetric stretch. The strong infrared band at $1053 \mathrm{~cm}^{-1}$ was attributed to a $\mathrm{C}-\mathrm{N}$ stretching vibration. A very strong and broad band from 3200 to $2100 \mathrm{~cm}^{-1}$ is the result of the anti-symmetric and symmetric stretching vibrations of the $\mathrm{O}-\mathrm{H}, \mathrm{N}-\mathrm{H}$ and $\mathrm{C}-\mathrm{H}$ bands. The shape and intensity of these bands agrees with the X-ray data, where an intricate network of hydrogen bonding is detected between $\mathrm{O}-\mathrm{H} \cdots \mathrm{O}$ and $\mathrm{N}-\mathrm{H} \cdots \mathrm{O}$. The presence of ammonium and imidazolium anions is also confirmed by the intense signal in the $2700-2100 \mathrm{~cm}^{-1}$ region he hydrogen assigned to the $\mathrm{N}-\mathrm{H}$ stretching vibrations of these ionic species. These signals are also broadened by the $\mathrm{N}-\mathrm{H} \cdots \mathrm{O}$ hydrogen bonding present in the crystalline material.

\subsection{Optical properties}

The crystals are broadly transparent, possessing a transmission greater than $70 \%$ for light with an incident wavelength between 250 and $1400 \mathrm{~nm}$. 


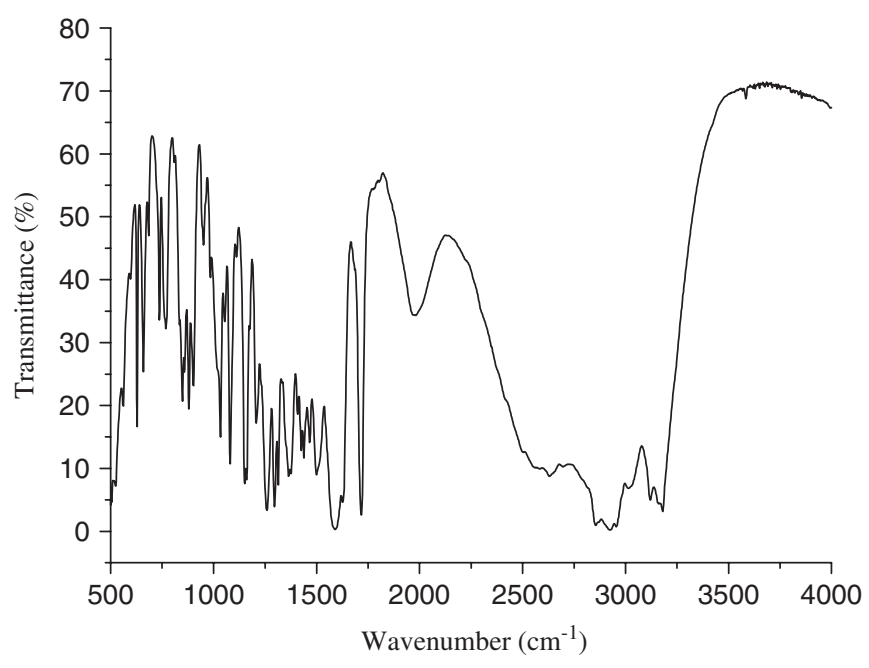

Fig. 7. infrared spectrum of L-histidinium hydrogen malate.

The powder SHG efficiency value relative to KDP is $d_{\text {eff }}=0.70 d_{\text {eff }}$ (KDP), similar to L-histidinium hydrogen tartrate $\left(d_{\mathrm{eff}}=0.79 d_{\mathrm{eff}}(\mathrm{KDP})\right)$ [29]. As is the case for two other salts containing the L-histidine cation, namely L-histidinium tartrate hemihydrate and the semi-organic L-histidinium tetrafluoroborate, the nonlinear optical properties are related with the delocalized $\pi$-electrons of the L-histidine cations and the hydrogen bonds present in the structures, as these also have an important contribution to the crystalline second-order nonlinear optical tensor coefficient in hydrogen bonded materials [39-41,46].

\section{Conclusion}

A new type of supramolecular network is present in L-histidinium hydrogen malate. The L-malate anions form 1-D hydrogen-bonded chains along [100], not aligned in a head-to-tail arrangement but in a head-to-side arrangement with the carboxylate $\mathrm{COO}^{-}$group of one anion, hydrogen bonded to the side hydroxyl $\mathrm{COH}$ of the neighbor. The strongest hydrogen bond in the structure is established between the cations and the anion; consequently, the $\mathrm{COOH}$ carboxylic group from the anion is strongly hydrogen bonded to the cation $\mathrm{COO}^{-}$group and not to that of the anion.

The L-Histidine cations form chains along [100] with the cations of adjacent chains aligned in an anti-parallel way, via two symmetry related $\mathrm{N}-\mathrm{H} \cdots \mathrm{O}$ hydrogen bonds.

In this rather complex and unusual crystal structure, the nonlinear optical properties of the imidazole ring are maintained in the solid state giving rise to a good secondharmonic generation signal. The efficiency for the nonlinear frequency conversion is similar to those of L-histidine tartrate and L-histidine tetrafluoroborate and consequently the material may find use in nonlinear optical applications.

The present material is an example where the canonical established rules for constructing supramolecular assemblies in compounds with monoanions of dicarboxylic acids do not hold true. As such it would be especially interesting to further explore other materials that result from synthesizing L-histidine with other dicarboxylic acids.

\section{Supplementary material}

Full crystallographic data (cif file) relating to the crystal structure have been deposited with the Cambridge Crystallographica Data Center as Data CCDC 296920. Copies of this information can be obtained free of charge from www.ccdc.cam.ac.uk/conts/retrieving.html or from Cambridge Crystallographic Data Centre, 12, Union Road, Cambridge CB2 1EZ, UK (Fax: + 441223 336033; E-mail: deposit@ccdc.cam.ac.uk).

\section{Acknowledgments}

This work was financially supported by FCT (Fundação para a Ciência e Tecnologia) and European Union Program FEDER, under the Project POCTI/FIS/33657/ 2000.

\section{References}

[1] G.R. Desiraju, Crystal Engineering: The Design of Organic Solids, Elsevier, Amsterdam, 1989.

[2] D. N Chin, J.A. Zerkowski, J.C. MacDonald, G.M. Whitesides, in: J.K. Whitesell (Ed.), Organised Molecular Assemblies in the Solid State, Wiley, New York, 1999, p. 185.

[3] M.C. Etter, Acc. Chem. Res. 23 (1990) 120.

[4] L. Leiserowitz, Acta Crystallogr. B 32 (1976) 775.

[5] J. Zyss, R. Masse, M. Bagieu-Beucher, J. Levy, Adv. Mater. 5 (20) (1993) 120.

[6] T.J. Marks, M.A. Ratner, Angew. Chem. Int. Ed. 34 (1995) 155.

[7] H. Kang, A. Facchetti, P. Zhu, H. Jiang, Y. Yang, E. Cariati, S. Righetto, R. Ugo, C. Zuccaccia, A. Macchioni, C.L. Stern, Z. Liu, S.-T. Ho, T.J. Marks, Angew. Chem. Int. Ed. 44 (2005) 7922.

[8] I. Ledoux, J. Zyss, C. R. Phyique 3 (2002) 407.

[9] Y.V. Pereverzev, O.V. Prezhdo, L.R. Dalton, ChemPhysChem 5 (12) (2004) 1821.

[10] L.R. Dalton, Pure Appl. Chem. 76 (7-8) (2004) 1421.

[11] Y. Liao, C.A. Anderson, P.A. Sullivan, A.-J.P. Akelaitis, B.H. Robison, L.R. Dalton, Chem. Mater. 18 (4) (2006) 1062.

[12] J. Zyss, I. Ledoux-Rak, H.-C. Weiss, D. Blaser, R. Boese, P.K. Thallapally, V.R. Thalladi, G.R. Desiraju, Chem. Mater. 15 (16) (2003) 3063.

[13] C. Feuvrie, I. Ledoux, J. Zyss, H. le Bozec, O. Maury, C. R. Chim. 8 (8) (2005) 1243.

[14] A. Facchetti, E. Annoni, L. Beverina, M. Morone, P. Zhu, T.J. Marks, G.A. Pagani, Nat. Mater. 3 (12) (2004) 910.

[15] C.C. Evans, M. Bagieu-Beucher, R. Masse, J.-F. Nicoud, Chem. Mater. 10 (3) (1998) 847.

[16] M. Muhuraman, R. Masse, J.-F. Nicoud, G.R. Desiraju, Chem. Mater. 13 (5) (2001) 1473.

[17] G.R. Desiraju, Angew. Chem., Int. Ed. Engl. 34 (1995) 2311.

[18] C.B. Aakeroy, P.B. Hitchcock, Acta Crystallogr. C 50 (1994) 759.

[19] J. Zyss, J. Pecaut, J.P. Levy, R. Masse, Acta Crystallogr. B 49 (1993) 334.

[20] C.B. Aakeroy, K.R. Seddon, Chem. Soc. Rev. 22 (1993) 397.

[21] S. Bhattacharya, P. Dastidar, T.N.G. Row, Chem. Mater. 6 (1994) 531.

[22] C.B. Aakeröy, A.M. Beatty, D.S. Leinen, Cryst. Growth Des. 1 (2001) 47. 
[23] A.D. Bond, W. Jones, in: W. Jones, C.N.R. Rao (Eds.), Supramolecular Organization and Materials Design, Cambridge University Press, Cambridge, 2002, p. 391.

[24] G.R. Desiraju, Acc. Chem. Res. 35 (2002) 565.

[25] J.C. MacDonald, B.B. Iversen, Angew. Chem., Int. Ed. Engl. 38 (1999) 1239.

[26] D.R. Trivedi, A. Ballabh, P. Dastidar, Cryst. Eng. Commun. 5 (64) (2003) 358.

[27] M.W. Hosseini, Acc. Chem. Res. 38 (2005) 313.

[28] C.B. Aakeroy, P.B. Hitchcock, K.R. Seddon, J. Chem. Soc., Chem. Commun. (1992) 553.

[29] C.B. Aakeroy, M. Nieuwenhuyzen, J. Am. Chem. Soc. 116 (1994) 10983.

[30] C.B. Aakeroy, P.B. Hitchcock, J. Mater. Chem. 3 (1993) 1129.

[31] C.B. Aakeroy, M. Nieuwenhuyzen, J. Mol. Struct. 374 (1996) 223.

[32] D.M.M. Farrel, G. Ferguson, A.J. Lough, C. Glidewell, Acta Crystallogyr. B 58 (2002) 530.

[33] D.R. Trivedi, A. Ballabh, D. Parthasarathi, Cryst. Eng. Commun. 5 (2003) 358.

[34] M.J. Kamlet, J.-L.M. Abboud, M.H. Abraham, R.W. Taft, J. Org. Chem. 48 (1983) 2877.

[35] R.J. Sundberg, I. Yilmaz, D.C. Mente, Inorg. Chem. 16 (1977) 1470.
[36] S.W. Santoro, G.F. Joyce, K. Sakthivel, S. Gramatikova, C.F. Barbas, J. Am. Chem. Soc. 122 (2000) 2433.

[37] J. Hirst, S.K. Wilcox, P.A. Williams, J. Blankenship, D.E. McRee, D.B. Goodin, Biochemistry 40 (2001) 1265.

[38] P. Deschamps, P.P. Kulkarni, B. Sarkar, Inorg. Chem. 43 (2004) 3338.

[39] H.O. Marcy, M.J. Rosker, L.F. Warren, P.H. Cunningham, C.A. Thomas, L.A. Deloach, S.P. Velsko, L.A. Ebbers, J.H. Liao, M.G. Kanatzidis, Opt. Lett. 20 (3) (1995) 252.

[40] K.V. Rajendran, D. Jayaraman, R. Jayavel, P. Ramasamy, J. Cryst. Growth 255 (3-4) (2003) 361.

[41] M.K. Marchewka, S. Debrus, A. Pietraszko, A.J. Barnes, H. Ratajczack, J. Mol. Struct. 656 (1-3) (2003) 265.

[42] J. Maddox, Nature (London) 335 (1988) 201.

[43] G.M. Sheldrick, SHELXL-97, A Program For Solution of Crystal Structures, University of Gottingen, Germany, 1997.

[44] A.L. Spek, PLATON. Molecular Geometry Program, University of Utrecht, Utrecht, The Netherlands, 1995.

[45] S.K. Kurtz, T.T. Perry, J. Appl. Phys. 19 (1968) 3768.

[46] J.M. Cole, J.A.K. Howard, G.J. McIntyre, Acta Crystallogr. B 57 (3) (2001) 410 . 